In CONSTRUCTIVISM IN PRACTICAL PHILOSOPHY, edited by Jimmy Lenman and Yonatan Shemmer, 180-194. Oxford: Oxford University Press, 2012.

\section{A Problem for Ambitious Metanormative Constructivism}

\author{
Nadeem J. Z. Hussain
}

\section{Introduction}

We can distinguish between what I will call ambitious metanormative constructivism and a variety of other constructivist projects in ethics and metaethics. ${ }^{1}$ To put the point roughly for now, ambitious metanormative constructivism is the project of either developing a type of new theory, worthy of the label "constructivism," that is distinct from the existing types of metaethical, or metanormative, theories already on the table-various realisms, non-cognitivisms, error theories and so on-or showing that the questions that lead to these existing types of theories, or the discussions that involve them, are somehow fundamentally confused. Natural ways of pursuing the project of ambitious metanormative constructivism lead to certain obvious, and related, worries about whether the ambitions are really being achieved-that is, whether we really are being given a distinctive theory-and whether such accounts ate viciously circular. I will argue that responding to these initial worries pushes ambitious metanormative constructivism towards adopting a kind of position that I will call "constructivism all the way down." Such a position does see off most, though not all, of the above initial worries. However, it faces a distinctive objection that is a descendent of Bertrand Russell's "Bishop Stubbs" objection against coherentist theories of truth. As it turns out, it is hard to tell whether the objection is fatal for ambitious metanormative constructivism; however, it shows, nonetheless, that a distinctive philosophical task needs to be carried out by such a constructivist before we will have any reason to think that such a theory can overcome the objection.

'The theories of concern to me are actually theoties that aim to provide a unified metanormative and metaevaluative account. However, I will be using two shorthands in this chapter. I will use "ambitious metanomative constructivism" to refer to such unified theories, and, instead of using some neologism such as metanormative and metaevaluative studies, or what have you, I will just refer to the relevant sub-discipline "metaethics."
For reasons of space, I will assume a general familiarity with the spirit of constructivist projects that take themselves to be, in some way or the other, challenging mainstream metaethical theories or theorizing. In what follows, I will be relying on this sense of the spirit of ambitious metanormative constructivism in order to rule out various ways of developing the metaphor of constructivism, or various ways of responding to objections to constructivism, as not being in this spirit. I will not have much to say here to someone who thinks that I am simply wrong about what motivates ambitious forms of metanormative contructivism. Similarly, constructivists who do not share those motivations will also have no reason to find much force in the objection I try to articulate.

\section{CONSTRUCTS}

Let us start with a very abstract schema for constructivist accounts for some domain $D$ of judgments:

(1) For any claim $P$ of some domain $D$, CONSTRUCTS (outcome $O_{P}$ is produced when a certain class of subjects $S$ follow procedure $R$ in conditions $C, P$ )

If for some proposition the CONSTRUCTS relationship is actually instantiated, then we can conclude that $P$. What precisely the CONSTRUCTS relation is will of course be part of what needs to be specified by some particular instance of the schema. For ease of exposition, I will occasionally talk of the "constructor" and the "constructee." The "constructor" is the first relatum in the above schema-it is what constructs $P$, the constructee.

I have put the schema in this abstract way in part because the English word "constructs," or the expression "is constructed by" forces one, like most terms for relations, to use a noun phrase to state the relata. And this in turn inevitably leads to expressions of the form such-and-such constructs the fact that $P$. One might worry that, despite whatever protestations to the contrary, talk of the fact that $P$ is already smuggling in realist assumptions. Instead the schema officially tries to leave open how we are to take the constructed item, and the constructor for that matter. I have also put the subscript " $P$ " on " $O$ " to mark that the outcome in question has to be appropriately discriminating between $P$ 's being the case and $P$ 's not being the case. ${ }^{2}$ For the purposes of my argument below, we can also allow the construction procedure

2 Cf. Mark Johnston's requirement that the response be " $x$-directed" (Johnston 1993, p. 103). I also do not mean to rule out accounts in which a single domain, in some intuitive sense, is divided into relevant subdomains with different subjects, procedures, and circumstances being relevant. For example, the fact that in general a batsman is not out when the ball touches the wicket as long as the bail is not completely removed from the top of the stumps is constructed by the relevant vote of the MCC; however, whether a particular batsman is dismissed, say, on a particular occasion can be a matter of whether the umpire has given him out on appeal. (Of course, that is not a necessary condition, since the batsman can be dismissed if he is out under any of the laws and chooses to leave his wicket.) 
to be indexed to the particular proposition or its subject matter. Thus, perhaps, the class of subjects, the procedures they follow, and their circumstances could all be topic specific. Nothing in the argument below turns on this not being the case; I have left out the relevant subscripts for simplicity's sake. ${ }^{3}$

Finally, for the kinds of accounts that concern us, the CONSTRUCTS relation will usually be a trans-world relation since the claim will not be that the outcome $O_{p}$ is produced in the actual world, but rather that it would be produced in the relevant possible world where a certain class of subjects followed the required procedure. Without this, depending upon the details, there will be hardly any facts of the matter for the domain or most claims will turn out to be false.

\section{Specifying ambitious metanormative constructivism}

One initial constraint on the relationship CONSTRUCTS is that the constructor should determine whether $P$ rather than simply reflecting an independently determined fact that $P$. In other words, there needs to be some sense in which $P$ is the case because the procedure has yielded the relevant result. We do not want it to be the case that the procedure yields this result because it is independently the case that $P$. To put the intuitive point a third way, we need to have the relevant kind of Euthyphro contrast maintained. ${ }^{4}$

Let me immediately rule out one relation, or perhaps family of relations, which would not give us ambitious metanormative constructivism. Plausibly for almost any normative or evaluative predicate $F$, if $x$ is $F$, then $x$ is $F$ in virtue of, given some other predicate $G$, $x$ 's being $G$. $G$ is $F$-making. These are forms of what Gideon-Rosen calls the "grounding idiom" (Rosen 2010). The serial killer is evil because he intends to kill the next hitchhiker he comes across. Take even the predicate " ... is a reason." Some consideration, that the grass is brown, say, can have the property of being a reason, say being a reason to water the grass. However, intuitively, the consideration will have the normative property of being a reason in virtue of some other property it has, say, the property of being what I desire not to be the case. ${ }^{5}$ Why do I say almost any normative or evaluative predicate? Well, we might think that there are some cases in which it is a bare or brute fact that something is good or bad. Perhaps, for example, pleasure's goodness. Is pleasure good in virtue of some other property of pleasure? Perhaps not. In any case, some such grounding relationship is one that every metaethical theory grants though different theories will have different accounts of it. ${ }^{6}$

${ }^{3}$ Compare the distinction Wright draws between "the Piercean biconditional for $\mathrm{P}: \mathrm{P}$ is true if and only if were $P$ appraised under conditions, $U, P$ would be believed," where $U$ are generally ideal conditions for inquiry, on the one hand, and a "corresponding Putnamian biconditional for $\mathrm{P}: \mathrm{P}$ is true if and only if were P appraised under topic-specifically sufficiently good conditions, $P$ would be believed" (Wright [1987] 2003, p. 293).

${ }^{4}$ Cf. Wright 1992, pp. 108-39.

5 Cf. Darwall 1998, p. 6.

6 Though not all may be able to do an equally good job (Dancy 2004).
I will also set aside some versions of constructivism that aim to provide metanormatively neutral constructivist accounts of relatively limited domains. Examples might be the constructivisms of Rawls and Scanlon. Whatever is the right way to interpret them the accounts I will put aside are accounts in which (i) the constructor is expressed in normative or evaluative terms, (ii) no metanormative account is given of the constructor, and (iii) the CONSTRUCTS relationship is not metanormatively insulating. In other words, for all the theory says, the constructee inherits whatever metanonnative account we give of the constructor. Such accounts do not attempt to carve out a new type of metanormative theory and so are not, for my purposes, metanormatively ambitious. (Which is, of course, not to say that they cannot be very ambitious, and very interesting, in other ways.)

Instead the constructivisms I am concerned with are those that are metanormatively ambitious in the precise sense that they aim to provide a new type of metanormative theory. In principle such constructivisms could be metanormatively ambitious about some particular domain; they could claim to be providing a metanormative theory that instantiates a new type of metanormative theory even though it is a theory for only some limited domain of normative or evaluative claims. However, I will focus here on theories that attempt to provide a constructivist account of the entire domain of practical normative judgments. ${ }^{7}$

\section{The relation and the relata}

What then are plausible accounts of the CONSTRUCTS relation for ambitious metanormative constructivism? An intuitive thought here is that the CONSTRUCTS relation is either identity or some close relation of constitution. ${ }^{8}$ We could try to capture this relation with identity combined with a subjunctive conditional: ${ }^{9}$

(2) $P=O_{p}$ would be produced were $S$ to follow $R$ in $C$.

Or perhaps a biconditional and some accompanying commentary:

(3) $P$ iff $O_{p}$ would be produced were $S$ to follow $R$ in $C$.

Both of these strategies generate further puzzles. Instead, I will use the subjunctive conditional on the right-hand side of these schemas but embed it in a negative

' One rationale for this focus is that most reasons for providing an ambitious metanormative constructivism for some particular domain of normative or evaluative claims are also reasons for providing such an account for the entire domain of practical normative claims. For reasons of space, I will not try to defend this claim here.

${ }^{8}$ An important additional possibility is the idea that the CONSTRUCTS relation actually provides somehow, or in effect, a distinctive account of the truth predicate for the domain in question. The discussion below will nor directly address this possibility though much of the discussion will be relevant to assessing any such account.

9 Recall the point I made earlier that the CONSTRUCTS relation would need to be trans-world. 
condition, a condition tailor-made for the specific purposes of ambitious metanormative constructivism:

(4) There is nothing more to its being the case that $P$ than that $O_{p}$ would be produced were $S$ to follow $R$ in $C$.

Even though I will use (4) in the discussion below, I will talk of the left-hand side (LHS) and the right-hand side (RHS) of such claims, where the left-hand side goes into the first slot in the following and the right-hand side into the second:

(5) There is nothing more to its being the case that... than that....

I should make clear that just because $P$ appears as a subscript to $O$ does not immediately mean that we have some kind of problematic circularity here. The theory needs a specification of the relevant outcomes, but it would require further argument to claim that such a specification does have to involve problematically appealing to $P$. I am also not assuming that the outcome would have to be a propositional attitude like a belief or a judgment. For example, we could allow for the outcome to be a non-cognitive attitude, an act, or even just behavior. What is required is that the theory be able to specify a sufficient number of these, so to speak-enough to give us outcomes for all the claims of the domain. If we do take the outcome to be a judgment or a belief with the content $P$ - the claim on the LHS-then there are some special puzzles that arise but I will again mostly ignore those puzzles here.

Now if the R.HS or constructor is specified in non-normative and non-evaluative terms (and assuming that no non-natural terms are used instead) we presumably just have a naturalistic reduction. ${ }^{10}$ Such reductions are quite ambitious, are metanormative accounts, and probably do deserve the label "constructivism" precisely because they might appropriately satisfy our schema. ${ }^{11}$ Most contemporary naturalist realisms in metaethics, such as those of Peter Railton or Michael Smith, might well be such forms of constructivism. Presumably most of us are such constructivists about the laws of cricket, for example-putting aside important concerns, for now, about whether the act of voting by a member of the MCC can be stated in non-normative and non-

10 Assuming also that no special problems are raised for the naturalism by the subjunctive conditional. Part of what would need to be assessed in further detail is whether the reduction is really a reduction to the features of the actual world that are in tum the reduction basis for the subjunctive conditional. Cf. Railton's approach in his reductive account of individual good: "what makes some or other end or activity be part of an individual's good is not the fact that he would, were he ideally informed (and so on), desire that his actual self pursue it, but rather the existence of the reduction basis for that counterfactual, namely, the particular constellation of law-governed features of the actual individual and his circumstances in virtue of which these claims about idealized hypothetical desires hold. Thus, the truth-condition of the claim thar such-and-such

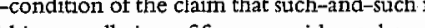
good for a given individual is directly given by the existence of this constellation of features, without detou through idealized desires" (Railton 2003, pp. 62-3).

Note that the strategy of finding a reducrion basis for the subjunctive in actuality is obviously not restricted to the naturalist.

"Appropriate satisfaction would require ensuring that the Euthyphro contrast is present. $\mathrm{Cf}$. Wright 1992, pp. 108-39. evaluative terms. However, any such constructivism would not be ambitious in the sense I am after since it would not be attempting to be an instance of a new type of metaethical theory (or be in the business of showing how mainstream metaethics is confused). Thus in order to have the kind of ambition I am looking for, we can put aside constructivist accounts in which the RHS of (4) can be stated in non-normative and non-evaluative terms.

Even if the RHS needs to be stated in normative or evaluative terms, this still leaves three basic options open. Assuming for the moment-controversially, no doubt-that there is a fundamental distinction between the normative or evaluative concepts of practical reason and those of theoretical reason, we can distinguish between RHSs that can be stated only in the normative or evaluative terms of practical reason, those of theoretical reason, or both. If the RHS could be stated only in terms of the normative or evaluative concepts of theoretical reason, then we would, in effect, have a reduction of practical normativity to theoretical normativity. What kind of metanormative account, if any, that would yield would then depend, not surprisingly, on what kind of metanormative account we gave of theoretical normativity. I, however, am not going to investigate that branch further explicitly because I suspect that most of us do not think that the practical can be reduced to the theoretical in this way. Such accounts are also not in the spirit of much that goes under the label of constructivism. In any case, much of what I will discuss in what follows can be applied to such accounts even if I do not take the space to do it explicitly here..$^{12}$

The accounts of interest here, then, are those in which the RHS above can only be stated using, in part, normative or evaluative terms of practical reason. Now, such an account seems not to be metanormatively ambitious since we still seem to need a metanormative account for the RHS. After all if the RHS is given, say, a noncognitivist reading, then, it seems, we will give the LHS a non-cognitivist reading.

Here, however, we need to note that our constructivist is committed to a certain claim anyway that might well provide a solution to just this worry. Recall that (4) is meant to hold of any normative or evaluative claim (of practical reason, that is, but I will leave off that qualification from now on). This now includes the RHS of (4). Thus the constructivist is committed to:

(6) There is nothing more to its being the case that $O_{p}$ would be produced were $S$ to follow $R$ in $C$ than that $O_{Q}$ would be produced were $S$ to follow $R$ in $C$

where $Q$ is just the claim that $O_{p}$ would be produced were $S$ to follow $R$ in $C$. (We see again how important it is that the theory be able to generate all the different outcomes it needs and how this might not be a trivial requirement.) The new RHS in (6) will be normative too, of course, and thus some version of the schema (4) will hold for it too

${ }^{12}$ I an :lso putting aside mixed accounts, though, again, much of what I say below would be quite relevant to assessing them. 
with another normative RHS. And so on. In this way we have a form of "constructivism all the way down." 13

As I said, it looks as though our constructivist is required to say this, but it also looks as though we might finally have the needed kind of ambition. When challenged with whether the RHS of any such identity is to be given a realist, non-cognitivist, or errortheoretic interpretation, the constructivist replies that the interpretation to be given is, of course, a constructivist one. There is no place-or no need-so the constructivist claims to tell any of the other stories.

Note that the goal here is not to provide an epistemic story on the behalf of the constructivist. The opponent whose challenges we are here concerned with is not necessarily one who questions the justifications of the relevant normative beliefs. Consider an analogy. I may completely grant that indeed there is a table in front of us and that you and I both have sufficient justification for our beliefs that there is such a table. However, I might think there are further questions about the constitution of tables or facts about tables. I might think that the following is a possibility we should consider:

(7) There is nothing more to its being the case that there is a table in front of us than that certain collections of atoms are arranged thusly.

You and I could disagree, or so I claim, about (7), but this is not a disagreement about whether there is a table in front of us and (7) need not be intended as an answer to any such potential disagreement. ${ }^{14}$ Rather, disagreement about (7) is the kind of disagreement we want to capture here: disagreement, say, about whether human practices of treating the relevant objects in certain ways are part of what make it the case that there is a table in front of us. The schema in (5) is selected precisely so that our ambitious metanormative constructivist can engage with the analogues issues in metaethics.

The ambitious metanormative constructivism I am attempting to articulate here is thus also not a form of quietism. The quietist constructivist, as I am, perhaps stipulatively, using the term, would deny that anything more than (4) needs to be part of the theory. Recall, however, that the pressure to include (6) comes from the apparent need to give a metanormative account of the RHS. As I pointed out earlier, the natural thought to have is that the constructee inherits whatever metanormative account we give of the constructor. And without a metanormative account of the RHS on behalf of constructivism, we seem to have left the field open to all the standard metaethical competitors. Since the relation represented by the schema in (5) is, as far as we have seen, not, to use my earlier locution, metanormatively insulating, whoever wins this

${ }^{13}$ Surely, one might claim, lots of non-normative facts are going to be part of what determines some normative matter in most cases-other than perhaps some subset of pure normative principles. We should not, however, worry that a schema like (6) must inevitably make the mistake of leaving these non-normative facts out. These can easily be written into the procedure $R$ and the circumstances $C$.

${ }^{14} \mathrm{My}$ thanks to a conversation with Elijah Millgram for prompting me to add this clarification. competition will then get to tell the metaethical story for the normative and evaluative claims of practical reason. Our constructivist would tum out, then, not to be metanormatively ambitious. Now there may well be some sound argument on the behalf of quietist constructivism that denies the need to go beyond (4); however, for the purposes of this chapter, I will not be developing or assessing that kind of view.

The form of constructivism "all the way down" that we have developed in this section, then, finally has the kind of metanormative ambitions I have been looking for. The question, of course, is whether there is a philosophically plausible account here.

\section{The problem}

It may seem obvious that there must be some vicious circularity or regress here; however, I think that any such charge takes some work to make it stick. To start with, note that (4) and (6) are not in the business of providing an informative analysis of normative concepts in the way in which that project is traditionally understood. There is no claim, for example, that someone who did not understand the concepts being used to state the LHS could nonetheless acquire such an understanding by seeing the presentation of the RHS.

Obviously, there is an epistemic question that any such constructivism must face: it must explain how we come to know (4), (6), and so on-the claims that constitute the constructivism "all the way down." Here the constructivist could appeal to conceptual truths but not ones that are meant to provide an analysis in the traditional sense. But note that the constructivist does not have to if he or she has some other account of how we could come to know these truths. For now let us just add the task of giving the needed epistemology or appealing to the epistemology of the conceptual to our to-do list. There are problems that will emerge here, but they are not the ones I want to focus on..$^{15}$

Instead, let us take the claim that:

(8) Bishop Stubbs was irrational.

(Practically, that is.) Now any particular way of filling out the scherna in (4) will give us a way of saying what the RHS is. The general schema would be:

${ }^{15}$ Perhaps the easiest response to epistemic worries is to claim that these are conceptual truths, but then any such account will face open-question style arguments. If these are not conceptual truths, then some othe epistemic story will need to be told. Since, in that case, these truths will themselves, for all that has been said so far, have to receive a constructivist account, the epistemic story will have to fit with this constructivist account. How all that would be made to work out is not something I will address in this chapter. For the purposes of this chapter, I will also ignore a range of potential problems lurking under the
traditional heading of the "Conditional Fallacy." For useful discussion of such matters in the context of rejections of realism, see Wright [1987] 2003 and Wright 1992, pp. 117-20. However, Wright's ow rejections of realism, see Wright [1987] 2003 and Wright 1992, pp. 117-20. However, Wright's own because it yields a fork, I suggest, for the purposes of ambitious metanormative constructivism precisely discourse is partially determined by best opinion" (Wright 1992, p. 120). 


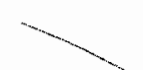

(9) $O_{(8)}$ would be produced were $S$ to follow $R$ in $C$.

And the relevant RHS for this in turn would be:

(10) $O_{(9)}$ would be produced were $S$ to follow $R$ in $C$.

And so on.

If asked why we do, or do not, think (8) in some everyday context, the natural response is of course to point to what Bishop Stubbs thought, did, or said. A metaethicist will, however, also want to know what kind of fact, if any, (8) is supposed to be, or what precisely we are doing when we apparently assert something like (8). In other words, the metaethicist will want to know what is the correct metanormative account for (8). As I mentioned above, certain kinds of quietism are certainly, to repeat the locution I used earlier, in the spirit of constructivism; however, our constructivist claims to have a positive, ambitious response to the metanormative question. One could simply assert an identity of (8) with propositions or facts about what Bishop Stubbs thought, did, or said. And, as I noted earlier, this would just mean that the metanormative question would have to be answered by looking closely at what we make of claims about what people think, do, or say-the metanormative task would just have been put off. Our earlier range of possibilities looms again. If we can give a non-normative account of what Bishop Stubbs thought, did, or said, then it looks like we have a reduction of the normative to the non-normative. If, on the other hand, it is a normative matter what Bishop Stubbs thought, did, or said, then, for all we have seen, the metanormative account of (8) will be determined by the metanormative account of what it is for someone to think, do, or speak. No distinctive metanormative account yet.

Our ambitious metanormative constructivist, however, is committed to constructivism all the way down. Thus, either right off the bat, or as an account of a supposedly normative account of thinking, saying, and doing, such a constructivist will point to something like (9). And when pressed on (9), again the constructivist will point to (10). And so on. ${ }^{16}$ And again the constructivist has to, in order to avoid one of the standard metaethical accounts. ${ }^{17}$

So far, no surprise. However, the problem is that a similar sequence can be constructed for the claim that:

36 Recall that the issue here is not epistemic

${ }^{17}$ Notice that this is why our constructivist cannot simply claim that the fact that the relevant procedure yields the required result is constituted just by that very same procedure yielding that very same result: for example, where $O_{(8)}$ and, the relevant procedures, etc. would just be identical to $O_{(9)}$, and so on. This would be equivalent to not having a response to the metanormative question about (9). Our ambitious metanormative constructivist has to be able to say something new - and recognizably constructivist-at each stage in order to defend the claim that he or she has a discinctive metanormative view. My thanks to Michael Bratman for raising the issue.

Of course, it should also be pointed out that in any case we would still have the symmetry that is the source of the problem I lay out in what follows.
(11) Bishop Stubbs was not irrational.

(12) $O_{(11)}$ would be produced were $S$ to follow $R$ in $C$.

(13) $O_{(12)}$ would be produced were $S$ to follow $R$ in $C$. And so on.

Now the intuitive thought, of course, is that both (8) and (11) cannot be the case. A natural reaction would be that what explains this is that only one of $(9)$ or (12) is the case. ${ }^{18}$ The natural reaction to have here is that surely as a matter of fact either $O_{(8)}$ or $O_{(11)}$ is produced when the relevant procedures are followed.

But, crucially, all that there is for it to be the case that either outcome is produced on the constructivists account is (10) or (13) respectively. And for these in turn all there is for them to be the case is that the next element in the sequence is the case. And so on. ${ }^{19}$

5.1 Russell's Bishop Stubbs objection to coherentism about truth

We can now begin to see why there might be an objection here that is a descendant of Bertrand Russell's "Bishop Stubbs" objection to coherentist theories of truth. Russell writes:

... the objection to the coherence theory lies in this, that it presupposes a more usual meaning of truth and falsehood in constructing its coherent whole, and that this more usual meaning, though indispensable to the theory, cannot be explained by means of the theory. The proposition 'Bishop Stubbs was hanged for murder' is, we are told, not coherent with the whole of truth or with experience. But that means, when we examine it, that something is known which is inconsistent with this proposition. Thus what is inconsistent with the proposition must be something true: it may be perfectly possible to construct a coherent whole of false propositions in which 'Bishop Stubbs was hanged for murder' would find a place. In a word, the partial truths of which the whole truth is composed must be such propositions as would commonly be called true, not such as would commoniy be called false; there is no explanation, on the coherence theory, of the distinction commonly expressed by the words true and false, and no evidence that a system of false propósitions might not, as in a good novel, be just as coherent as the system which is the whole of truth. (Russell 1906-7: 33-4)

Ralph Walker puts the natural response on the behalf of the coherentist as follows:

Russell thought this an objection to the coherence theory, but it is not, for the coherence theory is concerned with coherence not amongst arbitrary propositions, but amongst beliefs. (Walker 1997, p. 310)

${ }^{18}$ There is the separate question of whether the theory embodied by the two sequences is the correct theory for such claims and how we would know that. Here I am just assuming that we have the correct theory and, as I emphasized earlier, I am, for the most part, putting aside epistemic issues.

19 What about construction procedures that need to actually be carried out? It is hard to imagine an even remotely plausible account along these lines that would not lead to massive indeterminacy. More crucially, remower, for however, for reans already discussed, anb to its bein the case that the prosedure has vielded sould still outcome than that that, or some other, procedure has yielded the further relevant outcome. And so on. 
As Crispin Wright emphasizes in his assessments of Walker's discussions of coherentism, this is a particular instance of a general strategy that responds to Russell's worry by "earmarking certain propositions as in some way privileged" (Wright 1999, p. 220). ${ }^{20}$ So, for example, given our beliefs it just will not turn out that both "Bishop Stubbs was hanged for murder" and "Bishop Stubbs died of natural causes" are coherent with them. The privileging response thus disposes of the original Bishop Stubbs objection. ${ }^{21}$

Or so at least Walker seems to think..$^{22}$ As Wright points out in his critical study of Walker's book The Coherence Theory of Truth, this will depend in part on how coherence is eventually characterized (Wright 1995, p. 282). I will put this aside in order to focus on the objection Walker goes on to make against the privileging response. This is what Wright calls Walker's Master Objection to coherentist theories. As Wright's interpretive attempts make clear, there may well be several different objections lurking under this heading.

What lies at the heart of these concerns, though, is that if the coherentism is "pure" enough-to use Walker's phrase- a descendant of the Bishop Stubbs objection applies to the statements that make some propositions privileged. In the cases that Walker takes up, these are claims that a certain belief in one of the privileged propositions is actually held. For a pure coherentist, this too is a claim whose truth "must consist in coherence ... with the other beliefs that are also held" (Walker 1997, p. 316). However, the same applies to claims about these other beliefs. For Walker this means straightforwardly:

that the Bishop Stubbs objection recurs after all. We can easily denominate an arbitrary set of internally coherent propositions including "Bishop Stubbs was hanged for murder", such that for each proposition $p_{n}$ in that set, "It is believed that $p_{n}$ " coheres with the original set.... What the theory requires is that it should be a fact that certain things are believed, a fact that obtains in its own right and not in virtue of some further coherence. A pure coherence theory of truth, which holds that truth always consists in coherence, cannot accommodate this. (Walker 1997 pp. 316-17)

As Kirkham points out, the argument can be generalized so that it holds against any "pure" coherence theory with any account of what the designated set is. Thus we get the sequence:

$\mathrm{p}$ coheres with the designated set

' $\mathrm{p}$ coheres with the designated set' coheres with the designated set

etc. (Kirkham 1992, p. 115)

${ }^{20}$ For the point that it is not clear why Walker thinks that the "privileging response demands invocation of belief," see Wright 1995, p. 282.

${ }^{21}$ James Young calls the objection the "specification problem" and calls the privileging system of beliefs the "specified system" (Young 2001, p. 93).

22 As does Young 2001, p. 93

\subsection{Bishop Stubbs and ambitious metanormative constructivism}

Now, I should make clear that I do not think that the constructivist has to be committed to a coherence account of the property of being true, let alone a "pure" coherence theory. Indeed, it would probably be best for the constructivist to avoid any such controversial view. Thus our ambitious metanormative constructivism could be construed as the view that, for example, the proposition that Bishop Stubbs was always irrational is true because things are as it says they are, namely, that in fact Bishop Stubbs was always irrational. Constructivism would then be an account of the fact that Bishop Stubbs was always irrational. That fact that Bishop Stubbs is irrational just is the fact that the relevant outcome would be produced by the relevant procedure. ${ }^{23}$

In any case, what I do want to argue is that though our ambitious metanormative constructivist need not be a coherentist about truth, there is still a version, or a descendant, of the Bishop Stubbs objection that does apply to such a constructivism.

Return to our two sequences. All there is to its being the case that:

(8) Bishop Stubbs was irrational

is that it is the case that:

(9) $\mathrm{O}_{(8)}$ would be produced were $S$ to follow $R$ in $C .^{24}$

And all there is to its being the case that (9) is that:

(10) $O_{(9)}$ would be produced were $S$ to follow $R$ in $C$.

And so on.

Similarly all there is to its being the case that

(11) Bishop Stubbs was not irrational

is that:

(12) $O_{(11)}$ would be produced were $S$ to follow $R$ in $C$.

And all there is to its being the case that (12), is that:

(13) $O_{(12)}$ would be produced were $S$ to follow $R$ in $C$.

And so on.

The temptation is to say that only one of these sequences can be the case. ${ }^{25}$ But all there is for each member in the sequence to be the case is that the next member is the

${ }^{23}$ Put in this context, I do not think the term "fact" smuggles in ontological commitments of any kind that should actually be anathema to the spirit of constructivism.

${ }^{24}$ Again this does not immediately make what Bishop Stubbs thought, did, or said irrelevant since they could play some role in making it the case that the relevant outcome is produced by, for example, being considerations some set of ideal agents take into account in their deliberations. What our ambitious constructivist needs to avoid is some reduction just in these terms.

${ }^{25}$ Again, we are just assuming that we have the right constructivist theory of all the claims of the form (4). 
case. In this the two sequences are exactly the same. Thus by hypothesis there is no further feature in which one sequence's being the case, but the other's not being the case, could possibly consist. There is nothing this further fact of the matter could consist in.

Indeed, the ambitious metanormative constructivist may well, despite accepting a correspondence theory of truth, be in a situation worse than the coherentist about truth. James Young tries to argue against Crispin Wright, that once we allow the coherentist to make a distinction between giving an account of the truth of propositions and the obtaining of facts or states of affairs, then the coherentist does have a response to Walker's objection. The coherentist can claim that there are facts that determine the privileged system of propositions that are the propositions coherence with which is the property of being true. In order to maintain the purity of his or her coherence, such a coherentist would have to deny that, to put it in Kirkham's terms, the proposition that $p$ coheres with the designated set is true in virtue of corresponding to the fact that $p$ coheres with the designated set (Young 2001, p. 96). I suspect that thi an odder thing to say than Young lets on, but I will put that aside for now. ${ }^{26}$ For our purposes it is important to see that such a view will not help the ambitious metanormative constructivist since the relevant version of the Bishop Stubbs objection can be construed as applying directly to what is the case.

\section{Clarifications}

Further clarification of the kind of objection being aimed at the ambitious constructivist comes from attempting to use Frege's regress-which was aimled at any attempt to define truth-as the inspiration for an argument that attempts to show that there must be something wrong with my version of the Bishop Stubbs argument against constructivism. Note the sequence:

$\mathrm{p}$

It is true that $\mathrm{p}$

It is true that it is true that $p$

$\ldots$

Surely such a sequence can be constructed for any $p$ including both $p$ and not-p. However, it cannot be both the case that $p$ and the case that not- $p$.

Whatever the right thing to say about Frege's purported regress is in the context of giving an account of truth, I do not think this particular objection to my argument against ambitious constructivism does raise any genuine worry that we may have shown too much. Even if we take the fact that $p$ to be the same fact as the fact that it is true that $p$ and so on, we should grant that it is true that $p$ does not tell us what is to

${ }^{26}$ Walker rejects this option by claiming that the "coherence theory is a theory of facts as well as of truth" (318). be the case that $p$. That is why this sequence does not give us any insight into what kind of fact $p$ is, say, whether it is mind independent and so on. It presupposes some independent account of the fact that $p \cdot{ }^{27}$ The rest of the sequence is simply parasitic on whatever it is for $p$ to be the case. For our ambitious metanormative constructivist however, the sequence is meant to be an explanatory articulation of what it is for $p$ to be the case. There is no more fundamental account of what it is for each step in the sequence to be the case other than the next step in the sequence. And this is why a modified version of the Bishop Stubbs objection still applies.

In conclusion, I want to emphasize a couple of other points about the objection I am raising. First, the objection applies because our ambitious metanormative constructivist is, so to speak, "pure" enough. That is to say that though the constructivist may not aim to give a constructivist account of all claims-and thus is not the straightforward analogue of the "pure" coherentist about truth-our constructivist must give a constructivist account of all the claims in the sequence. This is because they all belong to the domain of practical normative and evaluative claims. Recall that were the constructivist to deny this then we would have a reduction to either the non-normative and non-evaluative or a reduction to theoretical normative and evaluative truths. I have not, of course, given any argument against such reductions but the loss of a particular kind of ambitiousness in taking those ways out is obvious.

Second, the objection is not that we have some unacceptable form of relativism. Charges of relativism do apply to specific versions of constructivism, including possible versions of ambitious metanormative constructivism. However, that is not the charge being placed here. The worry is not that Bishop Stubbs will be rational for some and not for others, but rather he will, so to speak, be both or neither for all of us.

Third, the objection is not that some purported analysis is circular or not explanatory in the way traditional analyses were meant to be. I am granting that what is being presented by the ambitious metanormative constructivist is not such an analysis. The problem is that at the most fundamental level there is nothing to make it the case that one normative claim is correct rather than another.

The above version of the Bishop Stubbs worry for ambitious metanormative constructivism has been pitched at a level abstract enough to allow for hope that some response could well be found. A lot more work would have to be done to show that we are even close to an impossibility proof. Nonetheless, I suggest that the constructivist should be quite concerned about how one might respond to this worry.

\section{References}

Dancy, Jonathan. 2004. "Discussion on the Importance of Making Things Right," in Ratio 17, pp. 229-37.

Darwall, Stephen. 1998. Philosophical Ethics (Bculder, CA: Westview. Press).

${ }^{27} \mathrm{Or}$, rather, it is not in the business of giving any further account of what it is for $p$ to be the case. 
Johnston, Mark. 1993. "Objectivity Refigured: Pragmatism Without Verificationism," in J. Haldane and C. Wright (eds), Reality, Representation, and Projection (Oxford: Oxford University Press).

Kirkham, Richard. 1992. Theories of Truth: A Critical Introduction (Cambridge, MA: MIT Press)

Railton, Peter. 2003. "Facts and Values," in Facts, Values, and Norms: Essays toward a Morality of Consequence (Cambridge: Cambridge University Press).

Rosen, Gideon. 2010. "Metaphysical Dependence: Grounding and Reduction," in Modality Metaphysics, Logic, and Epistemology, ed. Bob Hale and Aviv Hoffmann (Oxford: Oxford University Press), pp. 109-36.

Russell, Bertrand. 1906-7. "On the Nature of Truth," in Proceedings of the Aristotelian Society 7 pp. 28-49.

Walker, Ralph C. S. 1997. "Theories of Truth," in B. Hale and C. Wright (eds), A Companion to the Philosophy of Langrage (Oxford and Cambridge: Blackwell).

Wright, Crispin. 1992. Truth and Objectivity (Cambridge, MA and London: Harvard University Press).

Wright, Crispin. 1995. "Critical Study of Walker's The Coherence Theory of Truth," in Synthèse 103, pp. 279-302.

Wright, Crispin. 1999. "Truth: A Traditional Debate Reviewed," in S. Blackbum and K. Simmons (eds), Truth (Oxford and New York: Oxford University Press).

Wright, Crispin. 2003. "Truth as Sort of Epistemic: Putnam's Peregrinations," in Saving the Differences: Essays on Themes from Truth and Objectivity (Cambridge, MA: Harvard University Press).

Young, James O. 2001. "A Defence of the Coherence Theory of Truth," in Joumal of Philosophical Reseatch 26, pp. 89-101.

\section{Constructivism and Wise Judgment}

\author{
Valerie Tiberius
}

In this paper I introduce a version of constructivism that relies on a theory of practical wisdom. Wise judgment constructivism is a type of constructivism because it takes correct judgments about what we have "all-in" reason to do to be the result of a process we can follow, where our interest in the results of this process stems from our practical concerns. To fully defend the theory would require a comprehensive account of wisdom, which is not available. Instead, I describe a constructivist methodology for defending an account of wisdom and outline its main features. This gives us enough to see what wise judgment constructivism would look like, why it might be an attractive theory, and how it is different from other versions of constructivism.

\section{Introduction}

Should you brush your dog's teeth? My dogs absolutely hate teeth-brushing, but not doing so means they have to undergo general anesthesia every couple of years to have them cleaned at the vet, which they also hate. How hard should you try to avoid eating eggs from caged chickens? Is it enough to buy free-range eggs for home or should you also never eat another commercially baked cookie? Every member of a university department should do their share of service, but what exactly is your share? Must you accept nominations to important university committees in addition to your departmental service? Helping out family and friends is important too, but what if you are asked for financial help from a family member who has a history of gambling or drinking away his money? Or what if you are asked for your "honest opinion" about a friend's disastrous new dating partner? Or asked to choose sides in a conflict between two friends, one of whom has deeply hurt the other but in such a way that you cannot entirely blame her? What to do?

This question-"What to do?" or "What should I do?"-is a starting point in ethical theory. Kant thought it was the primary practical question. And for good reason: surveying the examples above, it does seem obvious that we confront this question on a regular basis. When we do-when we ask ourselves what we should do with family members who need help, or dogs who need teeth-brushing-we very quickly 